\section{Glasgow Caledonian University: impact of developing students' information literacy}

\author{
John Crawford
}

\section{Application of the Impact Implementation Initiative}

The objectives for Glasgow Caledonian University (GCU) were developed with and shared by Leeds Metropolitan University. These were

- To raise awareness of the importance of information literacy amongst students and academic staff

- To equip students with the skills to become independent seekers and discerning users of information in their studies

- To integrate information literacy into the student curriculum

- To enable graduates to be confident in their ability to use information in their work places and their lives

The action plan resulting from this consisted of the following

- Draft an information literacy policy for GCU

- Increase usage of electronic information services

- Incorporate information literacy into Personal Development Planning (PDP)

- Gather evidence that graduates feel confident in their ability to use information in their workplaces and their lives.

\section{Information Literacy policy}

This was progressed by a small working party which drafted a document, derived from that developed at LMU (LMU, 2003). Like the LMU document it is based on the SCONUL
Seven Pillars. This was presented to the appropriate University committee which decided that it did not fit into the University's Learning Teaching and Assessment Strategy. In view of the findings about the role of information literacy in the employability agenda (see below) it is likely that the issue can be most successfully progressed via the university's Partnership in Development (employability) agenda.

\section{Increase usage of electronic information services}

This was reviewed by a simple electronically administered survey based on the previous study of the usage of EIS (Electronic Information Services) (Crawford et al. 2004) but incorporating some questions on information literacy. This was administered electronically within the Library using the web based survey instrument, Survey Monkey, between Friday $20^{\text {th }}$ February 2004 and the following Tuesday by which time 451 responses had been obtained. Analysis shows a picture of gradual improvement in EIS usage but shows that the university environment as a whole is a powerful driver in the use of all IT based skills. A particularly good response was received from $1^{\text {st }}$ year students which showed them to be slightly more information aware than older students.

\section{Incorporate information literacy into Personal Development Planning (PDP)}

This was progressed initially by a focus group of academic staff held in December 2003 to get an initial idea of opinion. The main points emerging were:

- There is a need for a hierarchy of information literacy skills appropriate to different levels of student

- There is a need for communication between modules within a programme

- Information literacy (IL) must be embedded in the curriculum

- There is a key role for academic staff

- IL is a lifelong learning skill applicable in the workplace and the wider world

- EIS have bad points as well as good ones e.g. uncritical use - plagiarism 
GCU's current Learning, Teaching and Assessment Strategy (LTAS) intends the production of a PDP template to be used in all academic schools and support departments. There is more support for the idea in some Schools than others and while all universities will be obliged to offer PDP it is not compulsory and students will be under no obligation to accept it. Despite support from those committed to an innovative learning and teaching agenda this strategy is unlikely to be successful in the short term, at least.

\section{Gather evidence that graduates feel confident in their ability to use information in their workplaces and their lives}

This was researched by a questionnaire on information literacy to alumni. This was administered between about March and May 2004 using the University's alumni database which, despite being rather out of date, yielded about 450 excellent replies from both the UK and abroad. In general respondents showed a strong commitment to information literacy because they explicitly viewed it a skill which is increasingly sought by employers and consequently greatly enhances their career prospects and give them an advantage over other candidates for jobs or other work colleagues. The link to the employability agenda was notable. One respondent even said: 'If you can't do this you can't do anything'.

\section{Conclusions and interpretation}

GCU Library has a long tradition of survey and evaluation work and it was relatively easy to organise survey and evaluation within Learner Support. Influencing the University and piloting proposals through committees has proved much more difficult. The issue which has emerged clearly from all the studies mentioned above and also including another project involving a school, the Drumchapel project (McClelland, and Crawford 2004) is the emergence of the IL agenda. IL skills must be embedded into the curriculum and that this must begin at the secondary, not the tertiary stage.
In assessing the development of EIS usage and IL skills it is extremely difficult for any one agency to claim the credit. Students come to University with some skills although IL skills are probably the least developed. They are thrust into an environment where most services are IT based and IT skills are needed or have to be developed to use them. It is clear from the study of EIS usage by students that there is at GCU a hierarchy of usage by School, with paramedics at the top, followed by Business School students next and science and technology students last. Paramedicine is notable for its innovative learning and teaching agenda and its continuing relationship of learning and work after graduation. The hierarchy of usage also mirrors the University's retention and progression figures with paramedicine showing the best results and science and technology the worst. This suggests that the Library is linked to other factors and the greatest progress will be made where the commitment to learning and teaching is also greatest. The most important outcomes were not Value and Impact but the emergence of an information literacy agenda which has been shown to be intimately linked to the employability agenda.

\section{References}

Crawford, John et al. (2004), Use and awareness of Electronic Information Services by students at Glasgow Caledonian University: a longitudinal study, Journal of librarianship and information science, vol. 36, no. 3, pp. I0I-II7.

Leeds Metropolitan University. Learning Support Services (2003). Information literacy at Leeds Metropolitan University. Leeds: LMU.

McClelland, Dorothy and Crawford, John (2004) The Drumchapel Project: a study of ICT usage by school pupils and teachers in a secondary school in a deprived area of Glasgow, Journal of librarianship and information science, vol. 36, no.2, pp. 55-67. 